\title{
Inhaled Epoprostenol for Pulmonary Hypertension Treatment in Neonates: A 12-Year Experience
}

Frédérique Berger-Caron, $\mathrm{MD}^{1}$ Bruno Piedboeuf, MD, FRCPC ${ }^{2}$ Geneviève Morissette, MD, $\mathrm{FRCPC}^{3}$ David Simonyan, MSc ${ }^{4}$ Philippe Chétaille, MD, MSc ${ }^{5}$ Annie Pellerin, BPharm, MSc, BCPPS 6

Audrey Hébert, MD, FRCPC ${ }^{2}$

1 Department of Paediatrics, CHU de Québec, Université Laval, Québec City, Québec, Canada

2 Division of Neonatology, Department of Paediatrics, $\mathrm{CHU}$ de Québec, Université Laval, Québec City, Québec, Canada

${ }^{3}$ Division of Pediatric Intensive Care, Department of Paediatrics, CHU de Québec, Université Laval, Québec City, Québec, Canada

${ }^{4}$ Department of Biostatistic, Centre de recherche du CHUQ, Université Laval, Québec City, Québec, Canada

${ }^{5}$ Division of Pediatric Cardiology, Department of Paediatrics, CHU de Québec, Québec City, Québec, Canada

${ }^{6}$ Department of Pharmacy, CHU de Québec, Université Laval, Québec City, Québec, Canada

Am J Perinatol 2019;36:1142-1149.
Address for correspondence Audrey Hébert, MD, FRCPC, Department of Paediatrics, CHU de Québec, Université Laval, CHUL, 2705 Boulevard Laurier, Québec City, QC G1V 4G2, Canada (e-mail: audrey.hebert.2@ulaval.ca).

\author{
Abstract \\ Keywords \\ - pulmonary \\ hypertension \\ - neonate \\ - inhaled epoprostenol \\ - inhaled prostacyclin \\ - persistent pulmonary \\ hypertension of the \\ newborn \\ - oxygenation index
}

Background Persistent pulmonary hypertension of the newborn (PPHN) occurs in $10 \%$ of neonatal respiratory insufficiency. To selectively reduce pulmonary vascular resistance, several treatments have been tried. Inhaled epoprostenol $\left(\mathrm{iPGl}_{2}\right)$ has been used for 12 years in our institution for the management of refractory PPHN despite the gaps in the literature to support this use.

Objectives The primary objective was to evaluate the efficacy of $\mathrm{iPGl}_{2}$ for $\mathrm{PPHN}$. The secondary objectives were to describe its use in neonates and assess side effects. Study Design This retrospective cohort study included infants $<28$ days with PPHN treated with $\mathrm{iPGI}_{2}$ in the neonatal or pediatric intensive care units of our institution between 2004 and 2016.

Results We reviewed 43 patient' care episodes (mean gestational age of 36 weeks). This was an extremely ill population with $54 \%$ mortality rate. Oxygenation index improved significantly after 12 -hour treatment $(p=0.047)$, with a rebound effect when discontinuing nebulization. By the end of the therapy, the fraction of inspired oxygen had significantly dropped $(p=0.0018)$. Echocardiographic markers tended to normalize during treatment. No potential side effects were reported.

Conclusion In these sick newborns, we observed an improvement in PPHN under $\mathrm{iPGI}_{2}$ without significant adverse effects. To our knowledge, this is the largest neonatal cohort reported to have received $\mathrm{iPGI}_{2}$ for PPHN. received

July 31,2018

accepted after revision

October 19, 2018

published online

December 14, 2018
Copyright $\odot 2019$ by Thieme Medical

Publishers, Inc., 333 Seventh Avenue, New York, NY 10001, USA Tel: +1(212) 584-4662.
DOI https://doi.org/ 10.1055/s-0038-1676483. ISSN 0735-1631. 
Neonatal respiratory failure affects $2 \%$ of live births in addition to being the cause of over one-third of neonatal mortality. ${ }^{1}$ Persistent pulmonary hypertension of the newborn (PPHN) complicates the course of respiratory distress in approximately $10 \%$ of the infants. ${ }^{1}$ In its moderate to severe form, PPHN is associated with 5 to $10 \%$ of mortality and $25 \%$ of neurodevelopmental problems in children aged 12 to 24 months. $^{1}$

The goal for managing this condition is to selectively reduce pulmonary vascular resistance. ${ }^{2}$ Several treatments have been tried with mixed results, such as hyperventilation, bicarbonate infusion, and hyperoxia. ${ }^{3}$ Thus far, only one molecule has been approved by the Food and Drug Administration for the treatment of pulmonary hypertension in newborns: inhaled nitric oxide (iNO). ${ }^{4,5}$ iNO reaches well-ventilated areas of the lungs where it results in relaxation of the pulmonary vascular smooth muscles by activation of guanyl cyclase, leading to the production of cyclic guanosine monophosphate (cGMP). In a recent Cochrane Systematic Review, ${ }^{6}$ iNO improved outcomes in hypoxemic term and near-term infants by reducing the incidence of the combined end point of death or use of extracorporeal membrane oxygenation (ECMO). However, mortality was not affected.

In large randomized clinical trials, between 30 and $46 \%$ of infants with severe respiratory failure did not respond adequately to iNO. ${ }^{2,7}$ Others studies on this treatment had also reported no significant impact on mortality, length of hospital stay, or risk of long-term neurological abnormalities. $^{5,8}$ The metabolites of this molecule are toxic, ${ }^{2}$ and weaning may be problematic given the possibility of rebound pulmonary hypertension. ${ }^{8}$ Furthermore, this therapy has become very expensive, in addition to requiring expensive administration systems and monitoring which are not always available. ${ }^{2}$ These facts support the need for additional treatments to improve the prognosis of affected newborns.

Prostacyclins $\left(\mathrm{PGI}_{2}\right)$ have been studied, including epoprostenol (Flolan; GlaxoSmithKline Inc, Ontario, Canada) in animal and human models. $\mathrm{PGI}_{2}$ is an arachidonic acid metabolite formed by prostacyclin synthase that stimulates adenylyl cyclase in vascular smooth muscle cells, which increases intracellular cyclic adenosine monophosphate resulting in vasodilatation. ${ }^{7}$ A controlled study involving the continuous infusion of prostacyclins (ivPGI ${ }_{2}$ ) demonstrated a significant decrease in mortality in adults with pulmonary hypertension. ${ }^{9}$ However, their intravenous (IV) administration was accompanied by withdrawal reactions, tachyphylaxis, and systemic adverse effects due to the lack of pulmonary selectivity. ${ }^{10}$ ivPGI $_{2}$ causes significant systemic hypotension limiting its use in neonatology. ${ }^{10}$ Inhaled epoprostenol ( $\mathrm{iPGI}_{2}$ : using nebulized IV formulation) reduced pulmonary hypertension and improved patients' oxygenation without impacting systemic blood pressure. ${ }^{7}$ Metabolized in the lungs, its systemic absorption seems negligeable. ${ }^{4}$ However, very few cases of $\mathrm{iPGI}_{2}$ in neonatology have been reported. Available studies were mostly case reports with small sampling (maximum of 20 patients), newborns aged $>34$ weeks or pediatric population, with only a review of the short-term effect (hours) of $\mathrm{iPGI}_{2}$ using pre-established fixed doses and excluding diaphragmatic hernias and some congenital heart diseases. ${ }^{7,11-18}$

Nevertheless, $\mathrm{iPGI}_{2}$ has been used on a regular basis for the management of infants with refractory pulmonary hypertension in our institution in the past 12 years. This expertise has resulted in a standardized protocol that allows the treatment to be initiated within 30 minutes.

The objective of this retrospective cohort study was to evaluate the efficacy of $\mathrm{iPGI}_{2}$ as a rescue therapy for pulmonary hypertension of various etiologies in neonates. Secondarily, we assessed the potential adverse effects of this treatment and described its use in the study population. We hypothesized that $\mathrm{iPGI}_{2}$ would improve the condition of neonatal patients with pulmonary hypertension through selective pulmonary vasodilation, thereby reducing pulmonary arterial pressure without the major systemic effect observed with the IV administration.

\section{Materials and Methods}

\section{Study Population and Data collection}

This single academic center descriptive retrospective cohort study was approved by the local ethical committee. Infants less than 28 days of life who were hospitalized between 2004 and 2016 in either the neonatal or the pediatric intensive care units of our institution and who were treated with $\mathrm{iPGI}_{2}$ for a minimum duration of 1 hour were included. Subjects with inoperable congenital heart malformation were excluded, as well as patients with levels of care 2 and 3 (i.e., limited medical management precluding invasive therapeutic modalities). Fifty-seven potential study patients were identified as those having a prescription for $\mathrm{iPGI}_{2}$ in a computer-generated report from the pharmacy department database. Of these, two newborns had 2 separate care episodes analyzed independently, counting for 59 episodes of treatment in total. To ensure that all patients meeting the inclusion criteria were identified, we reviewed all the medical records of infants encoded for pulmonary hypertension and/or who received $\mathrm{iPGI}_{2}$ treatment as reported in the hospital archive summary report. Pulmonary hypertension was diagnosed on the basis of clinical presentation and/or objective echocardiographic measurements. Selected infants had available data for analysis of oxygenation index (OI) before, during, and after epoprostenol therapy. Patients who had received other treatments for PPHN before or during the epoprostenol treatment were included. Inclusion and exclusion criteria were then assessed. Eight patients, born before 2015 , were excluded due to lost of data in the chart (electronic file transition). Of those, five were postoperative cases of cardiac malformation and also rejected due to a postnatal age of more than 28 days. In addition, one received IV, and not $\mathrm{iPGI}_{2}$. Three were not neonates, but children or adults. Finally, the original prescription of $\mathrm{iPGI}_{2}$ was canceled in four cases.

A single investigator performed this detailed revision of the medical files manually. Afterward, the selected files were crosschecked. 


\section{Outcome Measures}

The main variable to assess the primary outcome was OI $\left(\mathrm{OI}=\right.$ mean airway pressure $\left.\times 100 \times \mathrm{PaO}_{2} / \mathrm{FiO}_{2}\right)$ calculated at baseline, during and after $\mathrm{iPGI}_{2}$ therapy using $\mathrm{PaO}_{2}$ values (partial pressure of arterial oxygen) from arterial blood gas and $\mathrm{FiO}_{2}$ values (fraction of inspired oxygen) from nurse's report. Clinically significant improvement was defined as a reduction of $20 \%$ or more of the OI from baseline based on an expert consensus within our academic center. A similar interpretation applied to the reduction of $20 \%$ or more of the $\mathrm{FiO}_{2}$ or to the increase of more than $20 \%$ of the $\mathrm{PaO}_{2}$. The following echocardiographic data were also collected: patent ductus arteriosus (PDA) or patent foramen ovale (PFO) shunt and ventricular septal motion.

Secondary outcome variables included: (1) need for ECMO, (2) renal function (urea/creatinine), (3) liver function (aspartate transaminase/alanine transaminase/bilirubin), (4) platelets count, (5) prothrombin time (PTT), (6) occurrence of bleeding, (7) significant ( $<$ third percentile for age) and sustained ( $>30$ minutes) decrease of systolic blood pressure (SBP), (8) impact on other vital signs (heart and respiratory rates, temperature, saturation, and blood glucose), and (9) mortality.

\section{Delivery of $\mathbf{i P G I}_{2}$}

$\mathrm{iPGI}_{2}$ was prepared from $0.5 \mathrm{mg}$ epoprostenol sodium (Flolan; GlaxoSmithKline Inc) dissolved with $5 \mathrm{~mL}$ of sterile diluent (glycine, sodium chloride, sodium hydroxide, and water). The reconstituted solution of epoprostenol had a pH of 10.2 to 10.8 . The solution was used within 24 hours when refrigerated or within 8 hours at room temperature. $\mathrm{iPGI}_{2}$ was administrated via Aeroneb nebulizer (GE Healthcare, Madison, WI) with Aerogen tubulure and syringes (Aerogen, Galway, Ireland) connected to the ventilator circuit and protected from light by a cotton diachylon. The initial dose of the continuous nebulization, $10 \mathrm{ng} /$ $\mathrm{kg} / \mathrm{min}$, was titrated to a maximum of $100 \mathrm{ng} / \mathrm{kg} / \mathrm{min}$.

\section{Statistical Analysis}

Quantitative variables are described as mean $\pm \mathrm{SD}$, and qualitative variables as frequencies and percentages. KruskalWallis'/Wilcoxon's rank-sum tests were used to compare continuous data by groups after normality verification; Pearson's chi-square or exact tests were used for categorical data comparisons. In case of multiple comparisons, Bonferroni's adjustment was applied. Generalized estimating equation (GEE) linear regression models were fitted to test repeated measures data. GEE correlation matrix structure was chosen by minimal quasi-likelihood under the independence model criterion. Specific period comparisons were done by paired Wilcoxon's signed-rank test. Finally, McNemar's tests were used to test dichotomized data by periods. Statistical analyses were performed using SAS Statistical Software v.9.2 (SAS Institute, Cary, $\mathrm{NC}$ ) with a two-sided significance level set at $p<0.05$.

\section{Results}

Fifty-seven medical records were identified from the pharmacy department database, corresponding to 59 episodes of treatment with $\mathrm{PGG}_{2}$. The search in the hospital's archives did not identify any additional files. Of these, 43 met the inclusion criteria (16 treatment episodes were excluded; see "Methodology" section for reasons of exclusion). Patient demographics, diagnostics, and outcomes are shown in -Table 1. Mean gestational age was 36 weeks, ranging from 24 to 42 weeks. The most common initial diagnostics were cardiac malformation (28\%) and idiopathic PPHN (26\%). Alongside $\mathrm{iPGI}_{2}$, all patients received other pulmonary vasodilators treatments. Initial PPHN treatment, started at mean postnatal age of 64 hours, was primarily iNO (88\%). During PPHN treatment, all patients received iNO, $49 \%$ received sildenafil, $40 \%$ received milrinone, $30 \%$ received bosentan, $28 \%$ received IV prostaglandins, and $5 \%$ other molecules. $\mathrm{iPGI}_{2}$ was started at a mean of 129 hours of life and titrated to an average maximal dose of $46 \mathrm{ng} / \mathrm{kg} / \mathrm{min}$. Patients received continuous nebulization for an average of 73 hours. The severity of the neonates' condition is demonstrated by the use of inotropes in $95 \%$ of cases, mainly dopamine (79\%) and adrenaline (71\%), and the $54 \%$ mortality rate (35\% per-treatment and $19 \%$ posttreatment). Two patients were on ECMO, but their data were excluded from the analysis due to important missing values and a postnatal age of more than 28 days in one case.

As shown in -Table 2, the mean OI prior to treatment was $35 \pm 25$ and decreased significantly to $26 \pm 15$ after 12 hours of $\mathrm{iPGI}_{2}(p=0.047)$. A rebound effect was observed at the end of the continuous nebulization with an increase in OI $(30 \pm 29, p=0.97$ comparing with OI 12 hours treatment), which was not sustained at 4 hours after the end of the treatment (OI: $14 \pm 7$ ). Oxygen requirements $\left(\mathrm{FiO}_{2}\right)$ decreased significantly between the beginning and the end of treatment ( $p=0.0018$ ). $\mathrm{PaO}_{2}$ tended to improve but was not statistically significant. A $20 \%$ improvement between baseline and 12 hours treatment values (-Table 3) was observed in $49 \%$ of patients for OI, $24 \%$ for $\mathrm{FiO}_{2}$, and $43 \%$ for $\mathrm{PaO}_{2}$. Generally, diaphragmatic hernia and meconium aspiration patients were best responders, with a $20 \%$ improvement of OI in 67 and 60\%, respectively. However, this distinctive response to $\mathrm{iPGI}_{2}$ based on the initial diagnosis was not statistically significant, with a substantial improvement of the OI also for cardiac malformation (55\%) and other diagnostics (50\%). Reversal of the right-to-left shunt via PDA occurred in $19 \%(p=0.083)$ of newborns and $6 \%$ via PFO $(p=0.48)$, which were not statistically significant (-Table 4). The normalization of ventricular septal motion occurred in $18 \%$ of infants $(p=0.25)$. Meconial aspiration patients tended to improve their echocardiographic parameters more than other diagnostics (-Fig. 1).

None of the 41 newborns (43 episodes of treatment) experienced side effects during $\mathrm{iPGI}_{2}$ therapy (-Table 5). No changes in renal and liver functions were documented. No cases of bleeding occurred. Platelets and PTT remained constant. Interestingly, all subjects remained hemodynamically stable with unchanged systolic arterial blood pressures and heart rates. Although not shown in tables, a significant decrease in heart rate occurred 4 hours postnebulization $(p=0.0047)$. There were no increased cerebral abnormalities as seen on cerebral ultrasounds. 
Table 1 Demographic values

\begin{tabular}{|c|c|c|}
\hline \multicolumn{2}{|l|}{ Components } & Values \\
\hline \multicolumn{2}{|c|}{ Total patients' care episodes } & 43 \\
\hline \multirow[t]{2}{*}{ Gender $^{\mathrm{a}}$} & Female & $18(42)$ \\
\hline & Male & $25(58)$ \\
\hline \multicolumn{2}{|l|}{ Apgar score $(5 \mathrm{~min})^{\mathrm{b}}$} & $6 \pm 3$ \\
\hline \multicolumn{2}{|l|}{ Gestational age $(w k)^{b}$} & $36 \pm 6$ \\
\hline \multicolumn{2}{|l|}{ Birth weight $(g)^{b}$} & $2,693 \pm 1,109$ \\
\hline \multirow[t]{5}{*}{ Initial diagnostics ${ }^{\mathrm{a}}$} & Idiopatic PPHN ${ }^{\mathrm{c}}$ & $11(26)$ \\
\hline & Meconial aspiration & $5(12)$ \\
\hline & Cardiac malformation & $12(28)$ \\
\hline & Diaphragmatic hernia & $6(14)$ \\
\hline & Others & $9(21)$ \\
\hline \multirow[t]{5}{*}{ First PPHN treatment ${ }^{\mathrm{a}}$} & iNO & $38(88)$ \\
\hline & Milrinone & $1(3)$ \\
\hline & $\mathrm{ivPGI}_{2}$ & $4(9)$ \\
\hline & Sildenafil & $0(0)$ \\
\hline & Epopostenol & $0(0)$ \\
\hline \multicolumn{2}{|c|}{ Age at initiation of 1st PPHN treatment (h of life) ${ }^{\mathrm{b}}$} & $64 \pm 120$ \\
\hline \multicolumn{2}{|c|}{ Age at initiation of epoprostenol (h of life) ${ }^{b}$} & $129 \pm 153$ \\
\hline \multicolumn{2}{|c|}{ Interval between 1st PPHN treatment and epoprostenol $(\mathrm{h})^{\mathrm{b}}$} & $61 \pm 65$ \\
\hline \multicolumn{2}{|c|}{ Initial epoprostenol dose $(\mathrm{ng} / \mathrm{kg} / \mathrm{min})^{\mathrm{b}}$} & $21 \pm 11$ \\
\hline \multicolumn{2}{|c|}{ Mean maximal epoprostenol dose $(\mathrm{ng} / \mathrm{kg} / \mathrm{min})^{\mathrm{b}}$} & $46 \pm 24$ \\
\hline \multirow[t]{8}{*}{ Received inotropes $^{a}$} & Total & $40(95)$ \\
\hline & Dopamine & $33(79)$ \\
\hline & Adrenaline & $30(71)$ \\
\hline & Milrinone & $19(45)$ \\
\hline & Noradrenaline & $11(26)$ \\
\hline & Hydrocortisone & $6(14)$ \\
\hline & Dobutamine & $2(5)$ \\
\hline & Vasopressin & $3(7)$ \\
\hline \multicolumn{2}{|c|}{ Duration of mechanical ventilation $(d)^{b}$} & $23 \pm 35$ \\
\hline \multicolumn{2}{|c|}{ Duration of oxygen therapy $(\mathrm{d})^{\mathrm{b}}$} & $21 \pm 35$ \\
\hline \multicolumn{2}{|c|}{ Duration of hospitalization $(d)^{b}$} & $32 \pm 37$ \\
\hline \multirow[t]{3}{*}{ Mortality $^{a}$} & Total & $23(54)$ \\
\hline & Per-treatment & $15(35)$ \\
\hline & Posttreatment & $8(19)$ \\
\hline \multicolumn{2}{|l|}{$\mathrm{ECMO}^{\mathrm{a}}$} & $2(5)$ \\
\hline
\end{tabular}

Abbreviations: ECMO, extracorporeal membrane oxygenation; iNO, inhaled nitric oxide; ivPGI 2 , intravenous prostaglandin; PPHN, persistent pulmonary hypertension of the newborn.

${ }^{a}(\%)$.

${ }^{\mathrm{b}}$ Mean $\pm \mathrm{SD}$

\section{Discussion}

This retrospective cohort study of 43 care episodes in neonates evaluated the efficacy of $\mathrm{iPGI}_{2}$ in the treatment of refractory pulmonary hypertension of the newborn and assessed its potential adverse effects to support its use in these critical situations. In keeping with our initial hypothesis, we found a significant improvement of OI after 12 hours of treatment ( $p=0.047$ ). Significant decrease of $\mathrm{FiO}_{2}$ by the end of treatment was also noted $(p=0.0018)$. Echocardiographic signs of pulmonary hypertension tended to recover with reversal of the right-to-left shunt via PDA and PFO and 
Table 2 Treatment efficacy

\begin{tabular}{|l|l|l|l|l|}
\hline Components & Pretreatment & 4 h per-treatment & 12 h per-treatment & Treatment end \\
\hline $\mathrm{OI}$ & $35 \pm 25$ & $31 \pm 20$ & $26 \pm 15^{\mathrm{a}}$ & $30 \pm 29$ \\
\hline $\mathrm{PaO}_{2}(\mathrm{~mm} \mathrm{Hg})$ & $53 \pm 50$ & $51 \pm 40$ & $54 \pm 37$ & $50 \pm 37$ \\
\hline $\mathrm{FiO}_{2}(\%)$ & $87 \pm 19$ & $82 \pm 19$ & $78 \pm 20$ & $71 \pm 26^{\mathrm{a}}$ \\
\hline
\end{tabular}

Abbreviations: $\mathrm{FiO}_{2}$, fraction of inspired oxygen; Ol, oxygenation index; $\mathrm{PaO}_{2}$, partial pressure of arterial oxygen.

Note: Mean $\pm S D$, paired $t$-test with pretreatment status.

${ }^{\mathrm{a}} \mathrm{p}<0.05$.

Table 3 Improvement $>20 \%$ of efficacy markers

\begin{tabular}{|l|l|l|l|}
\hline \multirow{2}{*}{ Initial diagnostics } & \multicolumn{2}{l|}{ Improvement $>\mathbf{2 0 \% ^ { \mathrm { a } }}$} & $\mathrm{FiO}_{2}$ \\
\cline { 2 - 4 } & OI & $\mathrm{PaO}_{2}$ & $8 / 34(24)$ \\
\hline Total & $17 / 35(49)$ & $15 / 35(43)$ & $1 / 7(14)$ \\
\hline Idiopatic PPHN & $2 / 8(25)$ & $3 / 8(38)$ & $1 / 5(20)$ \\
\hline Meconial aspiration & $3 / 5(60)$ & $3 / 5(60)$ & $5 / 11(46)$ \\
\hline Cardiac malformation & $6 / 11(55)$ & $2 / 11(36)$ & $1 / 3(33)$ \\
\hline Diaphragmatic hernia & $2 / 3(67)$ & $3 / 8(38)$ & $0 / 8(0)$ \\
\hline Others & $4 / 8(50)$ & 0.85 & 0.21 \\
\hline$p$-Value & 0.69 & & \\
\hline
\end{tabular}

Abbreviations: $\mathrm{FiO}_{2}$, fraction of inspired oxygen; OI, oxygenation index; $\mathrm{PaO}_{2}$, partial pressure of arterial oxygen; PPHN, persistent pulmonary hypertension of the newborn.

${ }^{a} n / N(\%)$ between start of treatment and 12 hours treatment based on an exact Pearson's chi-square test.

normalization of ventricular septal motion after epoprostenol therapy, without reaching the threshold of significance. These improvements prompt the consideration of $\mathrm{iPGI}_{2}$ to increase pulmonary vasodilatation in infants who remain hypoxemic despite the use of iNO. ${ }^{7}$ Prostaglandins and nitric oxide relax the vascular smooth muscles through two different second-messenger systems; therefore, in combination, iNO and $\mathrm{iPGI}_{2}$ may have synergistic effect. ${ }^{19}$ Moreover, infants with PPHN and inadequate response to iNO may have impaired cGMP-mediated pulmonary vasodilatation and may benefit from $\mathrm{iPGI}_{2}$, which acts through cAMP. ${ }^{7}$ No potential side effects were observed, especially no hemodynamic impact on SBP and heart rate. However, similar to Kelly et $\mathrm{al}^{7}{ }^{7}$ we observed transient deterioration in some infants when $\mathrm{iPGI}_{2}$ was discontinued. This rebound effect somewhat supports the effectiveness of $\mathrm{iPGI}_{2}$ but may also demonstrate temporary rebound pulmonary hypertension as observed with iNO. Nevertheless, these results do not reach the threshold of statistical significance. Otherwise, it was an extremely sick population with $54 \%$ mortality rate and two patients requiring ECMO. Nevertheless, it is difficult to stipulate the specific cause of death in this clinical context; $\mathrm{iPGI}_{2}$ was often a rescue therapy started when other treatment options had failed in newborns with critical condition.

These results are consistent with the few published case reports which have described the use of $\mathrm{PGI}_{2}$ in newborns and children with pulmonary hypertension. ${ }^{7,11-18}$ The use of epoprostenol was recently reported in five preterm neonates with infant respiratory distress syndrome or respiratory failure secondary to sepsis. ${ }^{11,12}$ All patients survived with the exception of one case of alveolar-capillary dysplasia. Kelly et $\mathrm{al}^{7}$ supported these findings by demonstrating sustained improvement of oxygenation in three of four term infants who had failed to respond to iNO following administration of milrinone and $\mathrm{iPGI}_{2}$. Two studies focusing on infants with pulmonary hypertension and congenital heart disease showed that epoprostenol and iloprost had a similar efficacy as pulmonary vasodilators. ${ }^{13,14}$ In addition, in 14 neonates and children with acute lung injury, $30 \mathrm{ng} / \mathrm{kg} /$ min $\mathrm{iPGI}_{2}$ significantly improved OI (26\%) compared with placebo $(p=0.001)$. The number needed to treat was $1.8 .^{15}$ No adverse effects were observed in this study. ${ }^{15} \mathrm{iPGI}_{2}$ was also associated with oxygenation improvement in two term infants with $\mathrm{PPHN}^{16}$ and one infant with congenital heart disease. ${ }^{17}$ Finally, Brown et al demonstrated that neonates may benefit more consistently from this therapy than older infants and children. ${ }^{18}$ Therefore, the available literature, mainly case reports, supports the conclusions of our retrospective cohort study.

In subgroup analysis, diaphragmatic hernia and meconium aspiration patients seemed to have better clinical responses based on an improvement $>20 \%$ of efficacy markers. Although these findings support current knowledge for meconium aspiration, such trend toward improvement was not expected with diaphragmatic hernia. The latter often does not respond much to other therapeutic modalities. 
Inhaled Epoprostenol for Pulmonary Hypertension Treatment in Neonates Berger-Caron et al. 1147

Table 4 Improvement of pulmonary hypertension echocardiographic signs according to paired McNemar's tests

\begin{tabular}{|l|l|l|l|}
\hline Echocardiographic parameters & Pretreatment & 24 h per-treatment & $p$-Value \\
\hline PDA right-to-left shunt (\%) & 41 & 22 & 0.083 \\
\hline PFO right-to-left shunt (\%) & 19 & 13 & 0.48 \\
\hline Flat or paradoxical septal motion (\%) & 61 & 43 & 0.25 \\
\hline
\end{tabular}

Abbreviations: PDA, patent ductus arteriosus; PFO, patent foramen ovale.

$\mathrm{iPGI}_{2}$ therefore, appears to improve their clinical status, but the number of patients of this study is insufficient to reach power for statistical means.

This study had some limitations. Our analyses were restricted by the retrospective nature of the study. Eight patients were excluded from all statistical analyses because of incomplete records. This had the effect of reducing our sample size and therefore, limited subgroup analysis (e.g., by differential diagnosis). Nonstatistically significant changes for some efficacy markers, including echocardiographic

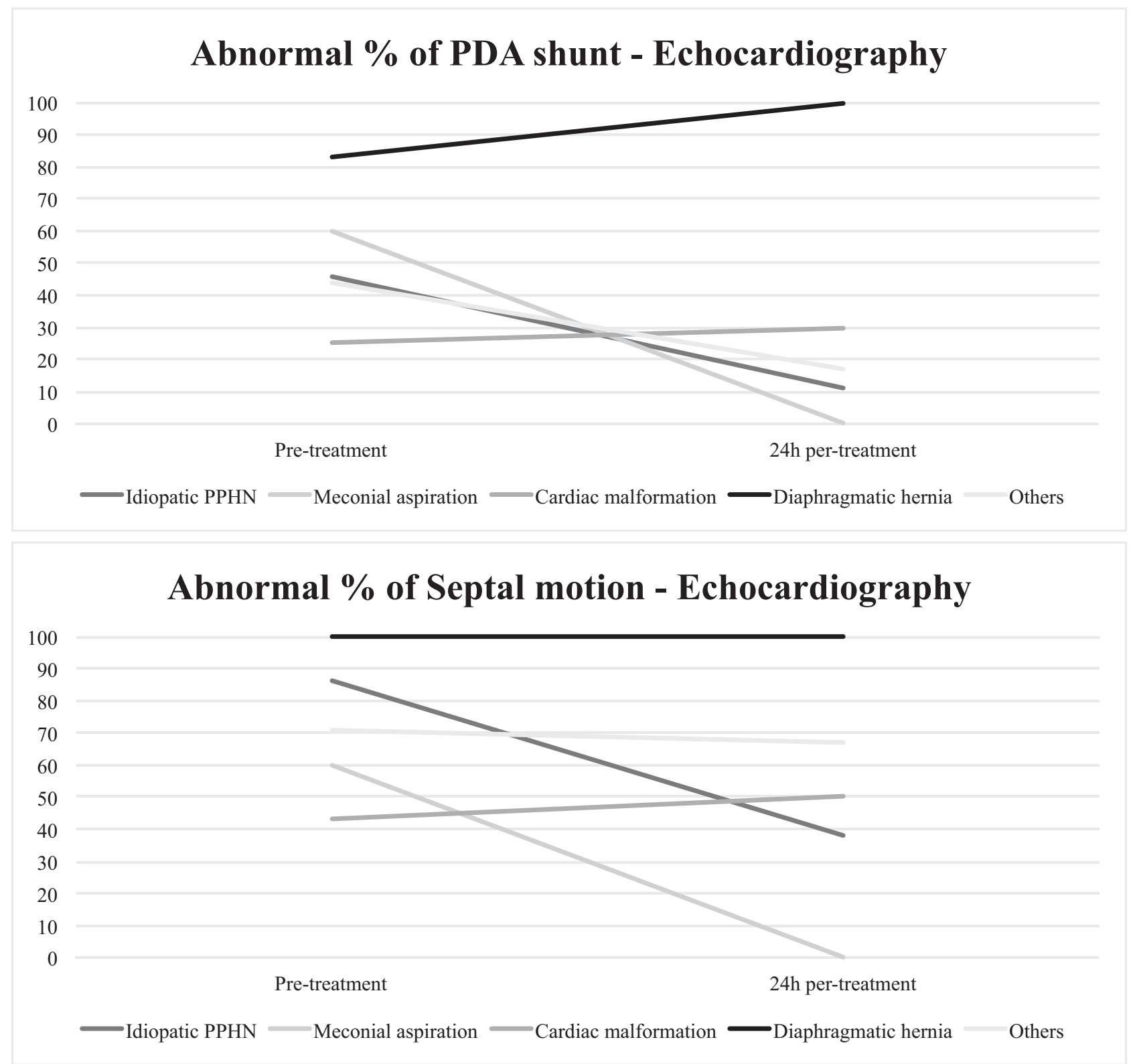

Fig. 1 Pulmonary hypertension echocardiographic signs. Pulmonary hypertension echocardiographic signs changes between start of the treatment and 24 hours per-treatment according to initial diagnostics, expressed as percentages of abnormal echocardiography for patent ductus arteriosus (PDA) and septal motion. Abnormal PDA shunt: PDA right-to-left shunt. Abnormal septal motion: flat or paradoxical septal motion. 
Table 5 Adverse effects

\begin{tabular}{|l|l|l|l|}
\hline Components & Before any treatment & Pretreatment & Posttreatment \\
\hline Creatinine $(\mu \mathrm{mol} / \mathrm{L})$ & $63 \pm 17$ & $62 \pm 21$ & $53 \pm 26^{\text {a }}$ \\
\hline AST $(\mathrm{U} / \mathrm{L})$ & $314 \pm 754$ & $189 \pm 596$ & $195 \pm 394$ \\
\hline ALT $(\mathrm{U} / \mathrm{L})$ & $80 \pm 198$ & $53 \pm 157$ & $92 \pm 197$ \\
\hline Platelets $\left(\times 10^{9}\right)$ & $176 \pm 95$ & $196 \pm 96$ & $200 \pm 95$ \\
\hline PTT $(\mathrm{s})$ & $42 \pm 16$ & $36 \pm 8$ & $45 \pm 36$ \\
\hline Systolic blood pressure $(\mathrm{mm} \mathrm{Hg})$ & $59 \pm 14$ & $62 \pm 15$ & $62 \pm 16$ \\
\hline Heart rate $($ bpm) & $150 \pm 23$ & $158 \pm 18$ & $153 \pm 23$ \\
\hline Transfontanelle ultrasonography abnormalities ${ }^{\mathrm{b}, \mathrm{c}}$ & $11 / 29(38)$ & $8 / 25(32)$ \\
\hline
\end{tabular}

Abbreviations: AST, aspartate transaminase; ALT, alanine transaminase; PTT, partial thromboplastin time.

${ }^{a} p<0.05$.

${ }^{\mathrm{b}} \mathrm{n} / \mathrm{N}(\%)$.

'All abnormalities were included.

signs, may also be attributable to missing data. There was no control over other PPHN treatments given to newborns studied, $\mathrm{iPGI}_{2}$ often being a rescue therapy. These molecules act on pathways related to PPHN and may interact with epoprostenol. Therefore, it is impossible to isolate the therapeutic effect of $\mathrm{PPGI}_{2}$ under these conditions. In addition, the absence of a placebo-controlled group made disease progression without $\mathrm{iPGI}_{2}$ difficult to predict and therefore limits our conclusion on the efficacy of the treatment. Currently, the IV formulation is used for nebulization, although its alkaline $\mathrm{pH}$ has been associated with irritation of the pulmonary epithelium and pulmonary hemorrhages. ${ }^{12}$ In past publications, the authors have highlighted the possibility of epithelium irritation due to the alkaline glycerine carrier of epoprostenol, without having studied it specifically. ${ }^{20}$ No cases have occurred in the past 12 years at our institution, but the supplier of IV epoprostenol has recently changed its formulation, which has become even more alkaline. This may compromise the use of this molecule if a specific formulation for inhaled therapy is not developed. Finally, we are aware that no hemodynamic impact was observed in our population in which the majority received inotropic agents concomitantly. However, inotropes were always started before nebulization and vital parameters remained stable over time.

Some strength distinguished this research from previous ones on this subject. The sample size was substantially larger compared with previous case reports. In addition, local expertise with $\mathrm{iPGI}_{2}$ administered according to a standardized protocol allows initiation of therapy within 30 minutes. This protocol reduces errors in administration of $\mathrm{iPGI}_{2}$. When started promptly in critical situations, the effectiveness of this treatment is potentially optimized. $\mathrm{iPGI}_{2}$ can be used without sophisticated technical equipment and seems less expensive than iNO. Although used as a rescue treatment in a very ill population, its efficacy was demonstrated by improvement of OI and the rebound effect. It appears as an interesting treatment option for PPHN without the adverse effects of IV $\mathrm{PGI}_{2}$ and iNO, as no hemodynamic impact on blood pressure and heart rate was reported.

\section{Conclusion}

In this very sick newborn population, we observed an improvement in PPHN with $\mathrm{PPGI}_{2}$ treatment without significant adverse effects. To our knowledge, this is the largest neonatal cohort reported to have received $\mathrm{iPGI}_{2}$ for PPHN. This study provides further evidence that $\mathrm{iPGI}_{2}$ may be safe in neonates and infants. A multi-institutional, prospective, randomized, controlled trial is needed to corroborate the findings of this retrospective study.

\section{Conflict of Interest}

None declared.

\section{Acknowledgments}

The authors would like to thank the Department of Pharmacy and the Department of Pediatrics of the Centre Mère-Enfant Soleil for their support in conducting this study, David Simonyan for statistical analysis, Josée Boulet for graphic design, Andrée Ayotte for her help in finding records, and all our collaborators who contributed to the revision of this project.

\section{References}

1 Steinhorn RH. Neonatal pulmonary hypertension. Pediatr Crit Care Med 2010;11(2, Suppl):S79-S84

2 Sood BG, Delaney-Black V, Aranda JV, Shankaran S. Aerosolized PGE1: a selective pulmonary vasodilator in neonatal hypoxemic respiratory failure results of a Phase I/II open label clinical trial. Pediatr Res 2004;56(04):579-585

3 Lapointe A, Barrington KJ. Pulmonary hypertension and the asphyxiated newborn. J Pediatr 2011;158(2, Suppl):e19-e24

4 Lowson SM. Alternatives to nitric oxide. Br Med Bull 2004;70(03): 119-131 
5 Jain A, McNamara PJ. Persistent pulmonary hypertension of the newborn: advances in diagnosis and treatment. Semin Fetal Neonatal Med 2015;20(04):262-271

6 Barrington KJ, Finer N, Pennaforte T, Altit G. Nitric oxide for respiratory failure in infants born at or near term. Cochrane Database Syst Rev 2017;1(01):CD000399

7 Kelly LK, Porta NFM, Goodman DM, Carroll CL, Steinhorn RH. Inhaled prostacyclin for term infants with persistent pulmonary hypertension refractory to inhaled nitric oxide. J Pediatr 2002; 141(06):830-832

8 De Luca D, Cogo P, Zecca E, et al. Intrapulmonary drug administration in neonatal and paediatric critical care: a comprehensive review. Eur Respir J 2011;37(03):678-689

9 Barst RJ, Rubin LJ, Long WA, et al; Primary Pulmonary Hypertension Study Group. A comparison of continuous intravenous epoprostenol (prostacyclin) with conventional therapy for primary pulmonary hypertension. N Engl J Med 1996;334(05):296-301

10 Barst RJ, Rubin LJ, McGoon MD, Caldwell EJ, Long WA, Levy PS. Survival in primary pulmonary hypertension with long-term continuous intravenous prostacyclin. Ann Intern Med 1994;121 (06):409-415

11 Soditt V, Aring C, Groneck P. Improvement of oxygenation induced by aerosolized prostacyclin in a preterm infant with persistent pulmonary hypertension of the newborn. Intensive Care Med 1997;23(12):1275-1278

12 De Jaegere AP, van den Anker JN. Endotracheal instillation of prostacyclin in preterm infants with persistent pulmonary hypertension. Eur Respir J 1998;12(04):932-934
13 Rimensberger PC, Spahr-Schopfer I, Berner M, et al. Inhaled nitric oxide versus aerosolized iloprost in secondary pulmonary hypertension in children with congenital heart disease: vasodilator capacity and cellular mechanisms. Circulation 2001;103(04): 544-548

14 Rashid A, Ivy D. Severe paediatric pulmonary hypertension: new management strategies. Arch Dis Child 2005;90(01): 92-98

15 Dahlem P, van Aalderen WM, de Neef M, Dijkgraaf MG, Bos AP. Randomized controlled trial of aerosolized prostacyclin therapy in children with acute lung injury. Crit Care Med 2004;32(04): 1055-1060

16 Bindl L, Fahnenstich H, Peukert U. Aerosolised prostacyclin for pulmonary hypertension in neonates. Arch Dis Child Fetal Neonatal Ed 1994;71(03):F214-F216

17 Zwissler B, Rank N, Jaenicke U, et al. Selective pulmonary vasodilation by inhaled prostacyclin in a newborn with congenital heart disease and cardiopulmonary bypass. Anesthesiology 1995; 82(06):1512-1516

18 Brown AT, Gillespie JV, Miquel-Verges F, et al. Inhaled epoprostenol therapy for pulmonary hypertension: Improves oxygenation index more consistently in neonates than in older children. Pulm Circ 2012;2(01):61-66

19 Lowson SM. Inhaled alternatives to nitric oxide. Anesthesiology 2002;96(06):1504-1513

20 De Luca D, Zecca E, Piastra M, Romagnoli C. Iloprost as 'rescue' therapy for pulmonary hypertension of the neonate. Paediatr Anaesth 2007;17(04):394-395 